
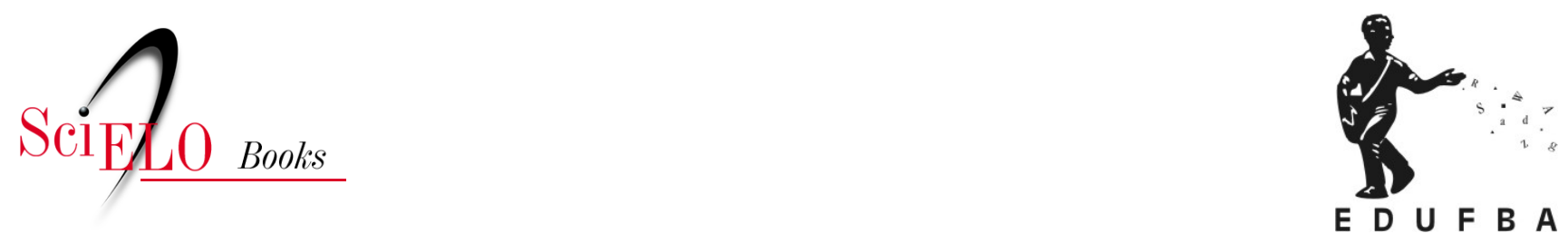

\title{
Pensar por constelações
}

\author{
Rita Velloso
}

VELLOSO, R. Pensar por constelações. In: JACQUES, P.B., and PEREIRA, M.S., comps. Nebulosas do pensamento urbanístico: tomo I-modos de pensar [online]. Salvador: EDUFBA, 2018, pp. 98-121. ISBN 978-85-232-2032-7. https://doi.org/10.7476/9788523220327.0005.

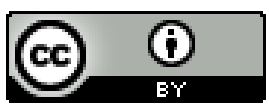

All the contents of this work, except where otherwise noted, is licensed under a Creative Commons Attribution 4.0 International license.

Todo o conteúdo deste trabalho, exceto quando houver ressalva, é publicado sob a licença Creative Commons Atribição 4.0. 
PENSA R PO R 


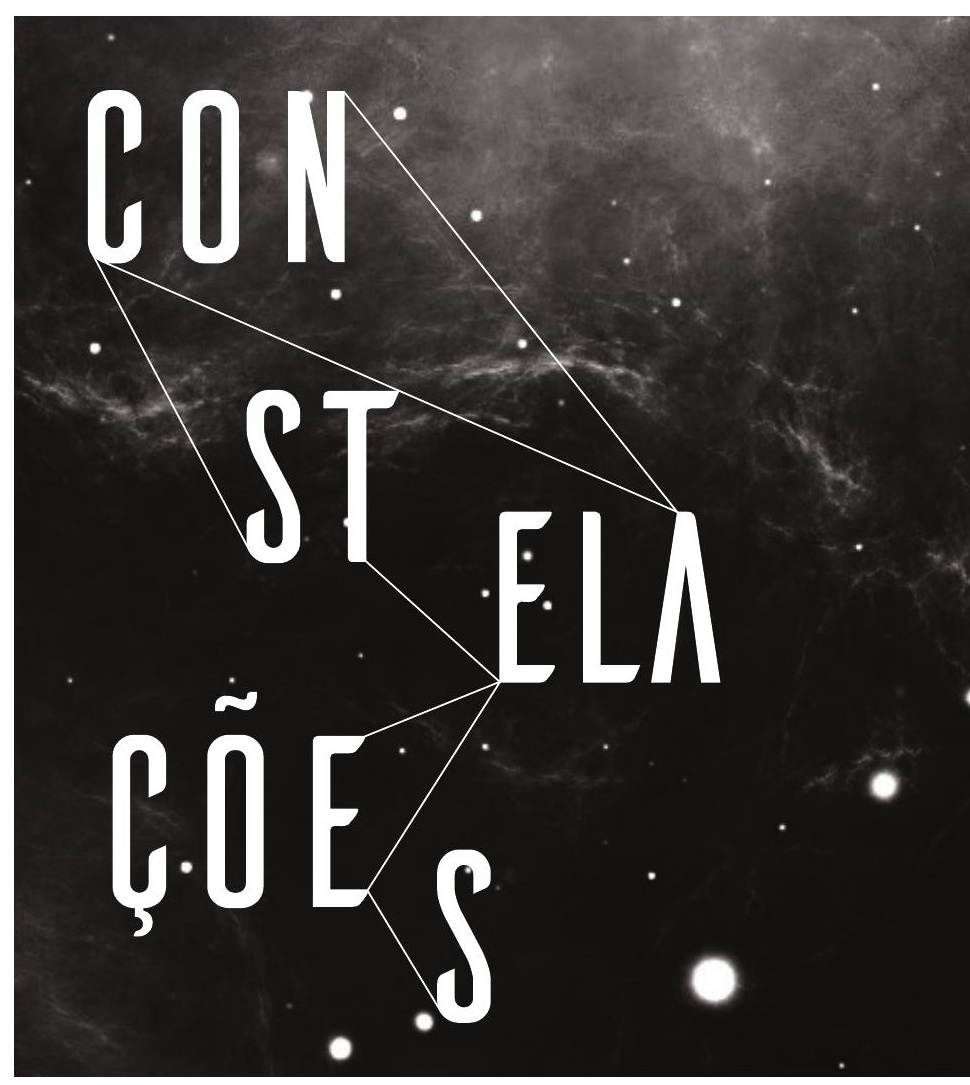




$$
\begin{aligned}
& P E N S \wedge R \\
& P O \mathrm{~A} \\
& \text { C O NSTELACOE S } \\
& \text { R I T } 1 \\
& V E L L O S O
\end{aligned}
$$


O que está fora de mim está justamente em mim, é meu - e inversamente' (Novalis, Encyclopédie)

O próprio da escrita é, a cada frase, parar para recomeçar. (BENJAMIN, 2011, p. 15)

\section{Hipótese}

0 termo "constelação" emerge numa acepção epistemológico-crítica na filosofia de Walter Benjamin (1892-1940) e ocupa um lugar importante em sua obra, seja na primeira fase de seus escritos, com o texto "Questões introdutórias de crítica do conhecimento", que abre a Origem do drama trágico alemão, publicado originalmente em 1925, sua tese de livre docência, seja nos textos finais, as notas para o Passagen-Werk (1927-1940) e as Teses sobre a história (1940).

Por “constelação", Benjamin designava a relação entre os componentes - as estrelas - de um conjunto - as linhas imaginárias que desenham um agrupamento constelar -, relação essa que se define não apenas pela proximidade entre as estrelas, mas também pela possibilidade de significado que o conjunto adquire, o sentido que lhe pode ser atribuído. 
A constelação é uma imagem na qual cada estrela, um singular, marca um extremo de linha que a liga a outra estrela, outro extremo singular. Nesse traçado de linhas imaginárias que delimita uma forma, uma configuração, não há um centro - com o que, tem-se, no centro da constelação sempre está o vazio. Essa imagem benjaminiana é bastante profícua quando se trata de imaginar um caminho ou a construção mesma do pensamento - o que faz Benjamin no seu prólogo ao Drama trágico é apresentar um programa para a própria escrita.

Para o filósofo alemão, as ideias se relacionam com as coisas assim como as constelações se relacionam com as estrelas. As constelações são ferramentas de um método. Coisas são o análogo das estrelas, e coisas são fenômenos particulares. Como tais, Benjamin precisa inserir esses particulares numa classificação. Assim, o filósofo se vale dos conceitos. Para classificar os fenômenos, conceitos são mediadores. Conceitos concretizam ideias, posto que são suas representações, são operadores do conhecimento e função do entendimento. ${ }^{1}$

No esforço da construção de um pensamento sobre o urbano com Walter Benjamin, muito embora não exclusivamente com ele, é necessário a meu argumento a estratégia benjaminiana segundo a qual os conceitos são construídos a partir dos extremos dos fenômenos - agrupando-nos para traçar distinções - a partir de suas diferenças, e não desde as homogeneidades.

Logo, para ver e falar sobre o urbano, devo colocar sob a lente não apenas a forma da cidade, sua ordenação física e seus desdobramentos materiais num determinado território - ou ainda os planos para seu desenvolvimento -, mas também aquilo que historicamente excedeu sua forma, seja enquanto crescimento desordenado, suas franjas e periferias, contrariando a ordem do desenho e do planejamento, como, ao mesmo tempo, a ação de seus habitantes, os conflitos, reivindicações, suas demandas por espaço, suas formas de vida.

Quando se trata de escrever sobre a espessura histórica de uma cidade ou de uma proposição urbanística, a constelação é uma estratégia de 102 pensamento de grande valia: permite pensar por extremos, desde os 
fragmentos, enfrentando a descontinuidade ou o vazio como algo incontornável no esforço do conceito.

A meu ver, a constelação do urbano e o método que lhe corresponde podem ser estudados, paradigmaticamente, em relação a algumas áreas de pensamento - filosofias da história e da linguagem -, a gêneros filosóficos e literários privilegiados por Benjamin - ensaio versus tratado, fragmento e citação, comentário e crítica - e a objetos urbanos específicos - dentre os quais estão a passagem, os monumentos, as barricadas - compreendidos como teoria. Em carta a Buber, em fevereiro de 1927, Benjamin afirma que deseja apresentar a cidade "sob o fato de que nela, 'todo fato já é teoria', e bastendo-se de qualquer abstração dedutiva, de todo prognóstico e, dentro de certos limites, de todo julgamento também”. (ROCHLITZ, 2003, p. 176)

Considerado o método de Benjamin no que diz respeito ao urbano, constata-se rapidamente que o problema da historicidade ocupa ali um lugar central. Segundo Molder (2010), a filosofia benjaminiana da história reposiciona a questão da origem: ao colocar a origem como um momento ou um instante originário, que se dá no fluxo da experiência atual para iluminar o passado e reciprocamente o presente, a origem é um fenômeno, aquele originário da história.

O conceito de origem ressurge na análise da forma-vida denominada "cidade". Se a origem é sempre histórica, pois se dá num momento específico, num contexto determinado, aqui me interessa refletir, a partir de Walter Benjamin, sobre um objeto específico - um conjunto de acontecimentos na história das cidades a que denomino "arquiteturas da insurreição”, designando o conjunto das lutas urbanas insurreicionais, acontecimentos esses que são parte componente da constelação do urbano na filosofia benjaminiana.

Trata-se de pensar uma escrita urbana por meio da narrativa "a contrapelo" de sua história, isto é, a narrativa das lutas urbanas segundo a constelação que as configura, quais sejam, num extremo a sua espacialidade (seus territórios e escalas) e, no outro extremo, os sujeitos que se empenham em lutar - sua linguagem, sua práxis comunicativa, sua organização em coletividades. 


\section{TEORIA URBANA}

Mas, de que urbano é possível falar, desde a matriz do pensamento constelar de Benjamin?

“Cidades são campos de batalha” (BENJAMIN, 2001, p. 165), ele escreveu ao comentar O livro de leitura para habitantes de cidades, de Brecht. Naquele "oceano de casas", onde homens e mulheres citadinos experienciam múltiplas e contínuas interações sociais, dá-se o epicentro do conflito social que surge da tradicional relação entre propriedade, poder político e poder econômico. Uma cidade, não obstante ser o lugar da luta (individual e coletiva) pela existência e da disputa entre classes sociais, exige que os indivíduos adaptem seus atos e suas disposições de espírito à sucessão de encontros casuais, habituais ou fortuitos. Viver num ambiente urbano implica a capacidade humana de construir laços, reconfigurar relações sociais e lidar com objetos e coisas em meio à vida cotidiana.

As diferenças entre grupos, entre indivíduos ou comunidades são reconhecidas e postas à prova continuadamente na cidade. As relações sociais se realizam, concretamente, na forma das relações espaciais, denotando o que se deve nomear por política do espaço. No uso da cidade por seus habitantes, isto é, na experiência da arquitetura urbana desempenhada por homens e mulheres na frequentação dos edifícios, colocam-se as possibilidades de negociação e o partilhamento de interesses comuns, privados e coletivos. Ocorre que, sendo da ordem do político, o espaço urbano é, por natureza, objeto de estratégias. Além disso, desde o início do século XX, o território de uma grande cidade tornou-se objeto de um planejamento referido à lógica do desenvolvimento econômico.

Isso implica que a vida urbana, para realizar-se plenamente, precisa desafiar, sucessiva e cotidianamente, a predominância de uma lógica que é da mercadoria. No cotidiano é que se dão os movimentos, as construções e as transformações na forma urbana: à vida cotidiana deve ser atribuída tanto uma ação - pelo que se torna necessário perguntar pelo(s) sujeito(s) que a desempenha(m) - quanto uma 104 concepção de posição: quando a experiência da arquitetura urbana 
desempenha-se no cotidiano como lugar de resistência e transformação, é a partir desse lugar que se pode criticar o arranjo capitalista que submete todas as esferas da vida, que se pode erigir o protesto contra a passividade que é inerente ao avanço tecnológico sobre as estruturas da vida cotidiana.

Ao urbanismo coube, desde o momento de sua constituição como disciplina, a ordenação física do ambiente material, e a ele foi dado exercer determinada forma de controle cujo desempenho configura parte fundamental na arquitetura do poder espetacular. ${ }^{2} \mathrm{O}$ urbanismo sempre foi uma estratégia de poder na sociedade denominada do espetáculo. Desde o segundo pós-guerra, com a reorganização das forças geopolíticas no Ocidente, no capitalismo ocidental tanto quanto nas experiências socialistas, a cidade tem se tornado parte do espetáculo em suas mais reconhecidas formas.

Uma proposição urbanística, em sua essência, é decisão sempre autoritária, afirmada para planejar o lugar como território da abstração. É força técnica da economia capitalista e salvaguarda do poder de classe, no cerne da pretensão capitalista de "colonizar o espaço", isto é, desenhar seu cenário na totalidade. Com os habitantes dispersos no espaço, suas mentes tomadas por preocupação em sobreviver minimamente, vivendo imersos em apatia, a cidade concebida no ideário funcionalista implica isolamento e integração na produção e no consumo aliado ao controle: ampliar os meios de manter a ordem na rua culmina, afinal, com a supressão da rua.

A cidade moderna, originariamente, decorreu dos processos de industrialização vigentes desde o século XVIII; por isso, chamamos de metrópole aquele território dominado pela técnica, no qual o capital se movimenta em meio a contradições.

Conforme afirmei acima, para Benjamin, "origem” é uma categoria histórica, e não uma categoria lógica - é um determinado passado que revela o presente a si mesmo. De tal forma que uma investigação começa quando o pesquisador demonstra que o fato que ele investiga possa revelar-se como um fenômeno de origem, algo autêntico - aquilo que se chama de selo de origem dos fenômenos, e sua descoberta será 
aquilo que traz à luz esse fenômeno -, seja através de experiências ou manifestações da consciência, possibilitando, contudo, o reconhecimento dos fenômenos que se relacionam em certas investigações. (BENJAMIN, 2011, p. 35)

a origem, mesmo sendo uma categoria histórica, não tem nada a ver com a gênese das coisas. A origem não designa o devir do que é nascido, mas aquilo que está nascendo no devir e no declínio. A origem é um turbilhão no fluxo do devir... em cada fenômeno de origem define-se a figura na qual uma idéia não cessa de cronfontar-se no mundo histórico até que ela se torne, se encontre incluída na totalidade de sua história. Em consequência, a origem não emerge de fatos constatados, mas ela toca sua pré e pós história. (BENJAMIN, 2011, p. 44)

Portadora das ideias de racionalização, a moderna arquitetura da cidade é a projeção, num território, das relações referentes à produção e ao consumo das coisas, com a consequente constituição de lugares diferenciados pelas funções que neles se exercem. A cidade é o meio em que o capital descobre o trabalho humano como riqueza. Henri Lefebvre (1999a, p. 86) observa que a cidade é o sujeito ao qual Marx imputa a dissolução do modo feudal e a transição para o capitalismo:

Como a terra em que se apóia, a cidade é um espaço, um intermediário, uma mediação, um meio, o mais vasto dos meios, o mais importante [...]. A cidade veicula as mudanças da produção, fornecendo, ao mesmo tempo o receptáculo e a condição, o lugar e o meio. [...] A cidade se torna, em lugar da terra, o grande laboratório das forças sociais.

A essência do processo de urbanização decorrente da industrialização é o espaço tornado mercadoria, e o solo parcelado é a substância da cidade que nasceu com a Revolução Industrial. Desde então, os processos urbanos são capazes de contar a história do capitalismo, pois a cidade é fenômeno de interação entre as relações de produção e forças produtivas, constituindo-se lugar da aglomeração das forças produtivas construídas pelo trabalho empregado no curso do pro106 cesso de circulação do capital. Por todos os lugares de uma cidade, 
evidenciam-se as relações materiais entre pessoas, assim como são inumeráveis, num ambiente urbano, os modos como relações sociais tornam-se relações coisificadas.

As relações sociais em torno da propriedade da terra e do solo, mais exatamente aquela relação social estreitamente ligada às forças de produção que impõe uma forma ao solo e à terra, podem ser consideradas parte da base econômica. Convertido em mercadoria, o espaço é produzido no interior de uma estratégia cujo fim é a acumulação de capital. Desse modo, o urbanismo é, essencialmente, uma ferramenta de transformação física na sociedade de consumo e resume-se a atuar como instrumento da regulamentação e administração do espaço construído.

A cidade moderna - à semelhança do Estado moderno e das instituições que o compõem - exigiu um espaço que pudesse ser organizado segundo suas próprias exigências econômicas, o que significou determinar a configuração daquele. Configuração resultante dessa dupla demanda (instituições e forças produtivas), o espaço da cidade tornou-se tanto um produto para ser usado e consumido como também um meio de produção. Mas se é verdade que a grande cidade é cumulativa de todos os conteúdos da vida prática - na simultaneidade que os caracteriza -, é também verdade que o mundo urbano dá-se num espaço a tal ponto dominado pela técnica que se arrisca, permanentemente, a não ser apropriado por seus habitantes, pois é sempre espaço na iminência de ser destituído da produção de relações livres de determinismos e constrangimentos.

O urbanismo moderno tomava a cidade-mercadoria como forma, isto é, objeto "definido e definitivo". Operando para ocultar e para dissimular a estratégia capitalista "sob uma aparência positiva, humanista, tecnológica”, o urbanismo

[...] oscila entre a representação de um vazio, quase geométrico, tão somente ocupado pelos conceitos, pelas lógicas e estratégias no nível racional mais elevado, e a representação de um espaço finalmente pleno, ocupado pelos resultados dessas lógicas e estratégias. (LEFEBVRE, 1999b, p. 141) 
A primazia do plano, princípio ordenador da arquitetura urbana da primeira metade do século XX, impunha-se como solução teórica; contudo, mascarava as contradições internas do espaço e concorreu para o predomínio de uma lógica da visualidade como elemento estruturador da cidade. $\mathrm{O}$ que os pensadores do urbanismo moderno oferecem é um espaço vazio, pretensamente neutro e apto a receber conteúdos fragmentados, configurando um ambiente em que objetos, pessoas e modos de vida pudessem ser simplesmente introduzidos. Ora, a neutralidade, uma ideologia em ação, é uma falsa hipótese. A teoria arquitetônica que pretendeu desenhar a cidade como sistema se serviu dos mesmos mecanismos do capitalismo que forjou, na modernidade, a sociedade burocrática de consumo dirigido.

A cidade moderna evoluiu suportada pela compreensão errônea de que seu espaço pudesse ser percebido na geometria abstrata de um plano, que separava e segregava funções. (LEFEBVRE, 1984) Um plano urbanístico pretende produzir lugares neutros, mas é sempre uma versão política impositiva de um modo de vida. Tudo se passava na cidade do funcionalismo, como se o espaço pudesse,

[...] de um modo mais ou menos harmônico, 'organizar' seus principais fatores: planos e unidades modulares, a composição e a densidade de ocupação, elementos morfológicos (ou formais) versus elementos funcionais. [...] $\mathrm{O}$ discurso dominante sobre o espaço - descrevendo o que é visto por olhos afetados por defeitos congênitos muito mais sérios que miopia ou astigmatismo - rouba a realidade do significado, vestindo-o um uniforme ideológico que não aparece como tal, mas ao contrário, dá a impressão de ser não-ideológico (ou então de estar 'além da ideologia'). (LEFEBVRE, 1999b, p. 317)

A cidade funcional explicitava a segregação no zoneamento, ${ }^{3}$ o qual é responsável precisamente pela fragmentação sob uma unidade frágil chamada tecido urbano, de um espaço tornado abstrato, repressivo em essência e par excellence. Fruto de uma racionalidade homogeneizante, que toma por suposto a existência de um grau zero do espaço, desde sempre definido pela tendência a neutralizar contradições e diferen108 ça da vida social, o zoneamento segrega por meio da localização, da 
imposição de hierarquia, enfatizando a produção e apropriação do espaço na cidade e seu entorno, privilegiando as exigências funcionais da indústria. A rigor, tratava-se de reproduzir a lógica da divisão técnica do trabalho na unidade fabril na organização socioespacial da cidade, pensando o espaço da reprodução social coletiva como extensão do espaço da produção e condicionando sua apropriação social ao funcionalismo produtivista da indústria e à lógica do mercado de terras e edifícios, privatizando e despolitizando assim a cidade e o espaço de vida.

Ao se fazer a crítica do urbanismo funcionalista, na matriz racionalista em que se figurou na primeira metade do século XX, é preciso recolocar em pauta a relação cidade-política - e é dela exatamente que Benjamin nos falava em sua estratégia-método de pensar por fragmentos em outras filosofias, de antes e coetâneas a ele. Senão, vejamos.

\section{Constelação do URbano}

Foi por um fragmento escrito em 1920-1921, em que se lia sobre a urgência da "troca de uma visão histórica do passado por uma visão política”, que Walter Benjamin começou a se ocupar da cidade. A culminacão dessa tarefa, para o autor, se daria na concepção da imagem urbana como montagem de tempos heterogêneos, já em 1929, no texto sobre o Surrealismo, e finalmente nas teses sobre a história, texto que datamos de 1940.

Para Benjamin, foi imperativa a tarefa de revelar a tradição que está no avesso dos discursos oficiais, pois é dessa revelação que se depreenderão o sentido e a consciência histórica para a humanidade. Há nessa ideia benjaminiana uma exigência de ruptura - a ruptura que desobscurece momentos escondidos, momentos decisivos que ficaram à sombra no curso do tempo. São momentos de interrupação libertadora do curso, para Benjamin, catastrófico, do curso das coisas. Se Benjamin recobra uma tradição, ela está oculta, oprimida, sempre ameaçada. É assim que o filósofo reivindica a visibilidade das revoltas descontínuas, de pronto recalcadas e esquecidas, difíceis de descobrir, mas vitais para o futuro da liberdade humana. 
Se viveu um tanto fascinado pela história em ruínas da capital do século XIX, Benjamin não a registrou somente por meio das lentes do materalismo histórico. É possível afirmar que, para sua escrita sobre Paris e tantas outras cidades, convergiu também o conceito de crítica vigente no Romantismo alemão sobre o qual se debruçara na tese de doutoramento. ${ }^{4}$ Ao pensar a cidade, o autor a considera - no escopo de sua teoria do conhecimento - um médium-de-reflexão. Objeto de sua filosofia quando dava início a uma abordagem materialista histórica da experiência estética, a cidade é ali analisada segundo estratégias de percepção, não de sua produção. Para tal, o filósofo mobiliza, no arranjo constelar, os conceitos de fantasmagoria, iluminacão profana, imagem dialética, ruptura.

Para o filósofo alemão, tratava-se, ao pensar a cidade, de pensar por imagens. Em outros termos, de construir o pensamento sobre a vida urbana a partir da visibilidade, isto é, pelo que dão a ver vestígios, cicatrizes, superposições, incompletudes, frestas. O que ganha relevo ao ler o pensamento-imagem-cidade benjaminiano é sua dupla fundação. Por um lado, fantasmagoria - a imagem que sobrevive no presente a nos dizer o futuro do pretérito de um lugar - e, por outro, fragmento - o que se nos deixa ver nos muitos tempos e idades de uma cidade.

Para Benjamin, há, como sabemos, uma dialética das imagens sem a qual a experiência do visível perderia sua força crítica, sua potência materialista. Nosso argumento, aqui, é que, ao tratar da experiência do visível, Benjamin confere a essa um novo estatuto, em que a imagem, fragmento e fantasma, é uma instância do pensamento que revoga a pretensão de sistema, remetendo ao inconcluso e informe do cotidiano como fonte e possibilidade de crítica, filosofia e poesia. Benjamin associou conhecimento a imagens dialéticas, ou seja, à presença de imagens relativas a diferentes experiências históricas presentes num mesmo momento, numa mesma constelação. A percepção destas imagens é possível porque elas não têm como origem o mesmo momento histórico; elas apenas se expressam em um mesmo momento histórico.

Para desdobrar os passos desse raciocínio, é preciso olhar para o 110 que Benjamin olhou, colocando em movimento tanto nosso tempo 
presente, como também a própria estratégia dialética (benjaminiana), na qual o presente é o tempo em que se realiza a iluminação profana que permite conhecer, que é condição do despertar.

A cidade-imagem benjaminiana é um tecido de cicatrizes e, como tal, fragmentos-fantasmas de tempos outros. É que a cidade, tal como a concebeu o filósofo alemão, é o lócus por excelência da "montagem de tempos" que se oferece à experiência, não apenas história objetificada. A imagem-cidade é um lampejo, um reflexo de luz que fulgura sobre as malhas da urbanidade para torcê-la, esgarçar seu tecido, instabilizar topografias, monumentos, edifícios, mercadorias, corpos, vazios, terrenos baldios. A imagem que Benjamin quer revelar está no avesso: há, ali em seu texto, uma exigência de ruptura, exigência de desobscurecer momentos que restaram escondidos e que ele entende como sendo decisivos.

Ao prospectar essa relacão imagem-cidade-montagem de tempos históricos, tem-se a importância central da imagem-fragmento na teoria benjaminiana; contudo, para compreender esse espaço imagético que é o núcleo da sua filosofia, foi preciso que nos debrussássemos sobre a concepção de fragmento de que fala o filósofo. ${ }^{5}$ Há, em Benjamin, segundo afirma João Barrento (2010), "o paradigma do fragmento”. Quando Benjamin reivindica uma tradição, ela está oculta, foi reprimida e somente pode retornar em tais momentos de “interrupção libertadora do curso das coisas". É desse modo que ele pode reivindicar a visibilidade das revoltas descontínuas, recalcadas ou esquecidas, mas necessárias ao futuro da vida livre nas cidades foi isso o que valorizou no Surrealismo:

ele foi o primeiro a encontrar as energias revolucionárias que aparecem no 'antiquado', nas primeiras construções de ferro, nas primeiras usinas, nas fotos mais antigas, nos objetos que começam a morrer, nos pianos de salão, nos vestidos de mais de cinco anos, nos lugares de reunião mundana quando eles começam a passar de moda. A relação desses objetos com a revolução, eis o que nossos autores compreenderam melhor do que ninguém [...] Eles fazem explodir as poderosas forças atmosféricas que esses objetos encobrem. 
O fragmento retoma, como expressão máxima de escrita e apresentação do pensamento, uma tarefa infinita que tende do individual ao universal, da forma de exposição à forma absoluta. $\mathrm{O}$ fragmento em seu "inacabamento essencial" (LACOUE-LABARTHE; NANCY, 2004, p. 4) faz-se "motor da busca incessante do sentido". (BARRENTO, 2010, p. 67) Em sua forma breve e transitória, crítica e ironia produzem o limiar entre filosofia e poesia. Pois, como escreveu Schlegel, citado por Benjamin (1993, p. 52): "A filosofia começa pelo meio [...]" ${ }^{6}$ A possibilidade de pôr em obra que a crítica romântica propõe e a poética aberta do fragmento tornam-se armas de combate.

A modernidade urbana europeia, desde os anos de 1750, marcada por grandes transformações sociais e perceptivas, tornou a questão da crítica e do conhecimento mais complexa.

Uma geração que ainda fora à escola num bonde puxado por cavalos encontrou-se desabrigada, numa paisagem que nada permanecera inalterado, exceto as nuvens, e, debaixo delas, num campo de forças de torrentes e explosões destruidoras, o frágil corpo humano. (BENJAMIN, 2012, p. 214)

Ao falar de sua atualidade, por meio da barbárie da guerra de 1914, bem como do que dela advém - pobreza, inflação, violência -, Benjamin expressava e radicalizava o sentimento moderno de exílio em seu próprio tempo, homogêneo e vazio, no qual se perdia progressivamente a capacidade de produzir experiências partilháveis, a capacidade real de comunicação numa sociedade que se esgarçava.

Para estudar as transformações da Paris capital, capturado pela poesia de Charles Baudelaire, Benjamin se debruça sobre o tema dos limites do conhecimento histórico, dessa vez escrevendo no exílio, durante o domínio nazista em seu país de origem. Nas Passagens, numa tentativa de compreender a mentalidade e a cultura oitocentistas, retoma determinadas afirmações do prefácio do Drama trágico alemão, dessa feita com algumas nuances. No início das notas do "Caderno N", 7 modula a ideia de conhecimento como "haver" ao afirmar que: "o conhecimento existe apenas em lampejos" e "texto é o trovão que segue ressoando 112 por muito tempo". Na segunda anotação, retoma a ideia do método 
como caminho indireto: "o que são desvios para os outros, são dados que determinam a minha rota”. (BENJAMIN, 2007, p. 499)

Além disso, o autor define a tarefa do projeto como uma aprendizagem por imagens históricas a fim de compreender as forças históricas atuantes, a consciência e a inconsciência das classes sociais, as contradições da modernidade ela mesma, para "[...] educar em nós o médium criador de imagens para um olhar estereoscópico e dimensional para a profundidade das sombras históricas”. (BENJAMIN, 2007, p. 500)

Esse aprendizado com imagens torna-se crítico à medida que se exercita um método designado por Benjamin como "montagem literária”, na qual se pode valer das imagens que ressoam nos textos, mas também nos edifícios, não aquelas valiosas e espirituosas, e sim os farrapos e resíduos, fazendo-lhes justiça. Desse modo, ao citar essas imagens-farrapos recolhidas no plano da experiência histórica, pretende produzir um desvio na própria legibilidade do mundo.

A montagem literária é a estratégia de escrita de uma história das imagens arruinadas. Benjamim pretende, assim, afastar-se da historiografia burguesa, linear, científica e causal, pautada na ideia de progresso, para aproximar-se de outra forma de escrita da história, a que conte a história dos vencidos, das coisas ínfimas que pereceram e perderam o valor no fluxo do tempo. Este modo de contar passa, fundamentalmente, por seu modo de apresentação na montagem, que se alia às composições artísticas das vanguardas, à lógica fragmentária do mosaico, como da arte da citação sem aspas e, sobretudo, como compromisso de atualização da história. Este movimento acontece erguendo "grandes construções através de elementos recortados com clareza e precisão [...] descobrir na análise do pequeno momento individual, o cristal do acontecimento total”. (BENJAMIN, 2007, p. 503)

Num movimento de atualização, Benjamin concebe o médium-de-reflexão como modo de utilizar modos diferentes de apresentação para núcleos distintos de reflexão, extraindo a criticabilidade da matéria com a qual se defronta. Em escalas de diferenciação, Benjamin vai da continuidade crítica romântica dos fragmentos à continuidade 
descontínua alegórica barroca nas ruínas e chega à descontínua continuidade das imagens dialéticas nas rememorações e montagens.

O espectro do fragmento como obra inacabada e abertura potencial atravessa o trabalho de Benjamin, atualizando-se nos núcleos de reflexão. O grande salto em relação ao primeiro Romantismo é o distanciamento da crítica que tende ao absoluto, lançando-a no campo da história materialista. Dessa forma, adiciona um terceiro termo à reflexão, radicalmente moderno e político, que já estava presente nos românticos, porém é recolocado de modo mais incisivo: a história. Enquanto os românticos esforçavam-se para unir filosofia e arte, pensamento e poesia, Benjamin interessava-se na força histórica desse procedimento e, no limiar do pensamento poético, queria extrair as energias revolucionárias para a escrita política da memória. Segundo Lowy (1990, p. 201), o Romantismo revolucionário de Benjamin se tece nas "relações dialéticas entre o passado pré-capitalista e o futuro pós capitalista, a harmonia arcaica e a harmonia utópica, a antiga experiência perdida e a futura experiência liberada".

\section{MÉTodo}

De acordo com Benjamin (2011, p. 14), a quintessência de seu método é a apresentação. Método ( $W e g$ ) é caminho indireto, é desvio (Unweg). Incansável, o pensamento começa sempre de novo e volta sempre, minuciosamente, às próprias coisas. No "Prólogo" do Drama trágico, o autor define que cabe ao âmbito filosófico o exercício da busca da apresentação da verdade, em contraposição à sua antecipação num sistema. Contra os sistemas filosóficos oitocentistas, que tentavam "se acomodar a um sincretismo que tenta capturar a verdade numa teia de aranha estendida entre varias formas de conhecimento, como se ela voasse de fora para cair ali”. (BENJAMIN, 2004, p. 14) De acordo com o filósofo, ao considerar um mesmo objeto nos vários estratos de sua significação, o pensamento toma fólego: recebe, ao mesmo tempo, um estímulo para o recomeço perpétuo e uma justificação para a intermitência de seu ritmo. (BENJAMIN, 2004, p. 15) Tal é 114 o sentido de seu pensamento constelar. 
A proposta de Benjamin é construir uma constelação que ofereça, sem descrevê-la, a imagem da verdade, e o método a ser utilizado é o da apresentação.

método deste trabalho: montagem literária. Não tenho nada a dizer. Somente a mostrar... Não surrupiarei coisas valiosas, nem me apropriarei de formulações espirituosas. Porém os farrapos, os resíduos: não quero inventariá-los, e sim fazer-lhes justiça da única maneira possível: utilizando-os. (BENJAMIN, 2006, p. 1030)

Tal apresentação exige a capacidade de perceber a verdade na forma produzida através da justaposição de elementos heterogêneos, que mostram o objeto de modo sempre novo. O movimento é comparado à construção do mosaico, no qual as imagens são produzidas a partir da justaposição de elementos isolados. A Benjamin interessa fazer ver que, nos mosaicos, quanto menor a relação dos fragmentos com a imagem resultante, maior será o valor de apresentação. Isto é, o valor da apresentação é inversamente proporcional à distância entre ela e os elementos que a compõem.

A imagem da constelação é elaborada no contexto de uma epistemologia proposta por Benjamin, como afirma Eagleton (1993, p. 239),

em que o conceito se funda não na ideia por trás do fenômeno como uma essência que o informa, mas, antes, na ideia como modo segundo o qual um objeto é configurado conceitualmente desde os seus elementos diversos, extremos e contraditórios.

Sua expectativa é de um materialismo da imanência no qual os menores objetos tragados pelo que chamam civilização - a história dos vencidos, sempre ocultada - e relegados pela própria dinâmica dessa construção histórica da destruição - a flecha sempre apontada para a frente, o progresso - pudessem revelar seus diversos aspectos, trazendo junto com seu abandono, sua redenção. É uma imagem da história radicalmente negativa e, ao mesmo tempo, profana; que se alimenta das imagens do passado, em busca da redenção da humanidade, e só 
essa humanidade redimida pode apropriar-se totalmente desse passado, conforme ressoa no conjunto das Teses sobre o conceito de história. Imagem que pode, afinal, preencher uma função revolucionária: a de arrancar do esquecimento o mundo urbano ainda presente, mas camuflado sob as ruínas de edificios ou em narrativas fraturadas, de falas cada vez menos proferidas.

O método da filosofia crítica benjaminiana, que formula conceitos estabelecendo um conjunto de correlações entre fenômenos, de modo a aproximá-los, sem, contudo, reduzí-los a uma unidade identitária, pode ser resumido numa afirmação do autor: "fórmula: construção por disposição e reunião de fatos”. (BENJAMIN, 2006, p. 1033)

Com todo o risco de conduzir sua construcão teórica a uma dificuldade irredutível diante de seus objetos históricos, a Benjamin interessa chegar ao conceito por meio de uma montagem, isto é, aproximando fênomenos em suas heterogeneidades. Ora, é exatamente na cidade onde dá a diversidade incontornável dos fenômenos que a caracterizam, que se justifica o emprego do método benjaminiano. Trazida à cidade, a empiria que funda a filosofia de Benjamin faz justiça à multiplicidade dos sedimentos da experiência urbana - a imagem, o tempo, a ação, a política -, em que se cruzam natureza e comunidade humana, artefatos e corpos, de tal modo que só poderá ser uma configuração de extremos historicamente específica. Uma constelação, afinal. 


\section{NOTAS}

1 "ideas are no more present in the world than constellations actually exist in the heavens, but like constellations they enable us to perceive relations between objects. It also means ideas are not the same as concepts, nor can they be construed as the laws of concepts. Ideas do not give rise to knowledge about phenomena and phenomena cannot be used to measure their validity. This is not to say the constellation is purely subjective or all in our heads. The stars in the night sky are where they are regardless of how we look at them and there is something in how they are positioned above us that suggests the image we construct of them. But having said that, the names we use for constellations are embedded in history, tradition and myth. So the constellation is simultaneously subjective and objective in nature. It is not, however, a system, and this is its true significance for Benjamin, who rejects the notion that philosophy can be thought of as systemic, as though it were mathematical or scientific instead of discursive. Benjamin developed this notion further in his account of the arcades in 19th-century Paris”. (CONSTELLATION, 2010)

2 Contudo, quando a população do mundo se torna preponderantemente urbana e a grande cidade explode em subúrbios, periferias, vazios urbanos ou pequenos aglomerados satélites; quando cada cidade pequena se transmuda em semicolônia da metrópole, o urbanismo formal expõe seu limite, vítima do próprio parâmetro da eficácia. É nesses campos urbanos que surge um novo gênero de existência social, dirá Guy Debord (1997, p. 173), como resultado da organização técnica do consumo. Para o teórico francês, na medida em que se caracterizava pela ditadura do automóvel, pelos indivíduos isolados em conjunto e pelos "hipermercados construídos em áreas afastadas, sustentados por estacionamentos, essas fábricas de distribuição” (DEBORD, 1997, p. 173), aquela arquitetura urbana vigente na Europa dos anos 1960 refletia a oposição - fundamental no espetáculo - entre atores e espectadores. Nos supermercados, nos arranha-céus e nos lugares de férias do tipo club mediterranée, figurações típicas da vida urbana, tornava-se evidente que a verdadeira dicotomia moderna situava-se entre organizadores e organizados. Conforme pensava Debord (1997, p. 173), compreender tal mundo urbano é compreender a dinâmica do consumo, que "está no primeiro plano da dissolução geral que levou a cidade a se consumir a si mesma”. Debord (1997) já demonstrava, em 1967, de que modo o urbanismo da cidade moderna colonizara o cotidiano implicando a banalização do espaço; agora, quando completa 50 anos a publicação de $\mathrm{A}$ sociedade do espetáculo e vivemos todos num mundo hiperurbanizado, o texto debordiano é mais atual que nunca, conforme atestam-nos as histórias e as teorias contemporâneas sobre a cidade. Dentre esses relatos, aqueles que se ocupam em fazer a crítica da cidade dominada pelas práticas do capitalismo são, em sua grande maioria, devedores do argumento debordiano de que viver alternativamente a uma tal colonização para superar a pretensão capitalista de desenhar o espaço em sua totalidade permanece como estratégia de resistência ao modo da vida espetacular. 
3 O zoneamento do uso do solo urbano é um instrumento da legislação urbanística de controle da cidade; surge na Alemanha do XIX e se desenvolve nos Estados Unidos. Implica a criação, amparada por lei, de zonas com regulamentos diferenciais, dividindo a cidade de forma conveniente para estabelecer os usos, regulamentando alturas e volumes, e deve garantir uma ordem disciplinária.

4 Walter Benjamin aproxima-se dos românticos de maneira radical em sua tese de doutorado, intitulada $O$ conceito de crítica de arte no romantismo alemão (1919). Nesse trabalho, apresenta a centralidade da ideia de crítica na teoria do conhecimento do primeiro romantismo alemão, sobretudo nas obras de Friedrich Schlegel e Novalis. Sua intenção era "reunir e intensificar certa noção de crítica de arte" (OLIVEIRA, 2006, p. 13), que, neste movimento, estava intimamente ligada à poesia e à literatura. A partir da análise deste processo central dos românticos, Walter Benjamin (1993) cunha o termo "médiumde-reflexão" (reflexionsmedium), para apresentar o núcleo de reflexão no qual a obra se transforma, fazendo dela mesma o médium da reflexão. $\mathrm{O}$ médiumde-reflexão, como determinação da arte, produz o conhecimento das obras por meio da crítica que se dá no trânsito entre a singularidade da obra e a infinitude da arte, tornando possível o seu desdobramento infinito e sua intensificação potencial. A obra, inacabada, reflete no médium a arte, conecta-se com outras obras e dá continuidade a sua forma rumo ao absoluto - percurso infinito e impossível.

5 Devo muito da argumentação e das formulações sobre o fragmento como estratégia textual em Walter Benjamin aos debates realizados com os pesquisadores Leonardo Izoton Braga, Laura Castro e Marina Moraes, no segundo semestre de 2017, por ocasião da nossa produção conjunta de textos sobre a filosofia benjaminiana.

6 O fragmento completo é: "Subjetivamente considerada, a filosofia sempre começa pelo meio, como um poema épico”. (SCHLEGEL, 1997, p. 60) Porém, utilizamos o recorte de Benjamin que potencializa a argumentação aqui referida.

7 O livro Passagens é dividido por temas em seções alfabeticamente distribuídas e numeradas, sendo o tema da seção N: teoria do conhecimento e teoria do progresso. 


\section{REFERẼNCI A}

NOVALIS. Encyclopédie. Paris: Les Éditions de Minuit, 1756. Fragmento 1753.

BARRENTO, J. O gênero intranquilo: anatomia do ensaio e do fragmento. Lisboa: Assírio \& Alvim, 2010.

BENJAMIN, W. Comentário aos poemas de Brecht. Revista inimigo rumor, Rio de Janeiro, n. 11, p. 151-179, 2001.

BENJAMIN, W. O conceito de crítica de arte no primeiro romantismo alemão. São Paulo: Iluminuras, 1993.

BENJAMIN, W. Experiência e pobreza. In: BENJAMIN, W. Magia e técnica, arte e política. Tradução de Sérgio Paulo Rouanet. São Paulo: Brasiliense, 1994. p. 114-119.

BENJAMIN, W. Origem do drama trágico alemão. Lisboa: Assirio e Alvim, 2004.

BENJAMIN, W. Passagens. Organização de Willi Bolle. Belo Horizonte: Editora da UFMG, 2006.

BENJAMIN, W. Prefácio epistemológico-crítico. In: BENJAMIN, W. Origem do drama trágico alemão. Edição e tradução de João Barrento. Belo Horizonte: Autêntica, 2011. p. 15-47.

CONSTELLATION. In: BUCHANAN, I. Dictionary of Critical Theory. Oxford: Oxford University Press, 2010. Disponível em: <http://www. oxfordreference.com/view/10.1093/acref/9780199532919.001.0001/ acref-9780199532919>. Acesso em: 12 dez. 2017.

DEBORD, G. Sociedade do espetáculo. Rio de Janeiro: Contraponto, 1997.

DUARTE, P. Estio do tempo: romantismo e estética moderna. Rio de Janeiro: Zahar, 2011.

EAGLETON, T. O rabino Marxista. In: EAGLETON, T. A ideologia da estética. Rio de Janeiro: Jorge Zahar Editor, 1993. p. 230-246.

GAGNEBIN, J. M. História e narração em Walter Benjamin. São Paulo: Perspectiva, 1999. 
LACOUE-LABARTHE, P., NANCY, J. L. A exigência fragmentária. [S.I.: s.n] 2004.

LEFEBVRE, H. A cidade do capital. Rio de Janeiro: DP\&A, 1999a.

LEFEBVRE, H. Critique of everyday Life. New York: Verso, 1991.

LEFEBVRE, H. La vida cotidiana en el mundo moderno. Madrid: Antropos, 1978.

LEFEBVRE, H. Production of space. Oxford: Blackwell, 1984.

LEFEBVRE, H. Quotidién et quotidienneté. In: ENCYCLOPAEDIA universalis. Paris, 1972.

LEFEBVRE, H. A revolução urbana. Belo Horizonte: Editora da UFMG, 1999b.

LOWY, M. Romantismo e messianismo: ensaios sobre Lukács e Benjamin. São Paulo: Perspectiva, 2001.

LUKÁCS, G. História e consciência de classe. São Paulo: Martins Fontes, 2002.

MACHADO, F. de A. P. Imanência e história: a crítica do conhecimento em Walter Benjamin. Belo Horizonte: Editora da UFMG, 2004.

MOLDER, M. F. Método é Desvio. In: OTTE, G.; SEDLMAYER, S.; CORNELSEN, E. Limiares e passagens em Walter Benjamin. Belo Horizonte: UFMG, 2010. p. 27-75.

OLIVEIRA, B. B. C. de. Olhar e narrativa: leituras benjaminianas. Vitória: EDUFES, 2006.

OTTE, G.; SEDLMAYER, S.; CORNELSEN, E. Limiares e passagens em Walter Benjamin. Belo Horizonte: UFMG, 2010.

ROCHLITZ, R. O desencantamento da arte: a filosofia de Benjamin. Bauru: EDUSC, 2003.

SCHLEGEL, F. O dialeto dos fragmentos. São Paulo: Iluminuras, 1997.

SELIGMANN-SILVA, M. O local da diferença: ensaios sobre memória, arte, 120 literatura e tradução. São Paulo: Ed. 34, 2005. 
SELIGMANN-SILVA, M. Walter Benjamin e os sistemas de escritura. Revista Remate de Males, Campinas, 2012.

SHERINGHAM, M. Everyday life: Theories and practices from Surrealism to the Present. Oxford: Oxford University Press, 2006. 